[DOI: 10.24214/jecet.A.8.2.16066.]

Jaurnal of Enviranmental Science, Computer Science and Engineering \& Technology

\author{
An International Peer Review E-3 Journal of Sciences and Technology
}

Available online at www.jecet.org

Section A: Environmental Science

Research Article

\title{
The transformation of natural gas and methanol on bimetallic zeolite catalysts
}

\author{
E.A. Qanbarova, T.A. Babayeva, N.F. Akhmedova, S.E. Mirzaliyeva, S.E. Mamedov \\ Baku State Universitet, Azerbaijan, AZ1148, Baku. Z.Khalilov 23
}

Received: 07 March 2019; Revised: 26 March 2019; Accepted: 04 April 2019

\begin{abstract}
The catalytic properties of mono- and bimetallic catalysts based on zeolites of the ZSM-5 type, obtained by solid-phase modification methods with $\mathrm{Mo}, \mathrm{Cr}, \mathrm{Ni}, \mathrm{Zn}$ and $\mathrm{V}$ nanopowders in the conversion of natural gas and methanol components to aromatic hydrocarbons, are studied. It was shown that the addition of a second modifier element to a $40 \% \mathrm{Mo} / \mathrm{HZSM}-5$ monometallic catalyst leads to an increase in its activity and selectivity in the process of converting the components of natural gas and methanol to aromatic hydrocarbons. The maximum yield of benzene is observed on a bimetallic catalyst containing $1.0 \mathrm{wt} . \% \mathrm{Cr}$ nanopowder and at $750^{\circ} \mathrm{C}$ it is 14,4 wt. \% with a selectivity of $80,7 \%$. On the yield of benzene, the catalysts are arranged in a row: $\mathrm{Cr}$ Mo/HZSM-5 $>$ Zn-Mo/HZSM-5>Ni-Mo/HSZM-5.Determined that on the methanol convertion, an increase in the content of $\mathrm{Cr}, \mathrm{Ni}, \mathrm{Zn}$ and $\mathrm{V}$ nanopowders in the composition of catalyst $4.0 \% \mathrm{Mo} / \mathrm{HZSM}-5$ to $4.0 \mathrm{wt}$. \% leads to a noticeable decrease in the yield of ArH and an increase in selectivity for $\mathrm{p}$-xylene. According to the selectivity of the formation of p-xylene, the catalysts are located in a row: V-Mo/HZSM-5 $>\mathrm{Zn}$ Mo/HZSM-5>Cr-Mo/HZSM-5>Ni-Mo/HSZM-5 on a bimetallic catalyst containing $4.0 \mathrm{wt}$. \% of vanadium, the selectivity for p-xylene reaches $72,5 \%$.
\end{abstract}

Keywords: natural gas, methanol, bimetallic zeolite catalysts, aromatic hydrocarbons, nanopowders of tungsten and nickel 


\section{INTRODUCTION.}

Under the conditions of the growing shortage and high cost of oil, its replacement to alternative sources of cheaper and more accessible raw materials and first of all to gas state hydrocarbons, is topical. These hydrocarbons are contained in natural and associated gases ${ }^{1,2}$. A promising raw material for the production of valuable hydrocarbons is also methanol, which is an intermediate product in the conversion of natural gas according to the scheme

$$
\text { Natural gas } \longrightarrow \text { synthesis gas } \longrightarrow \text { methanol } \longrightarrow \text { olefinic hydrocarbons }{ }^{3,4} \text {. }
$$

In this connection, the catalytic method of converting the components of natural gas and methanol to aromatic hydrocarbons $(\mathrm{ArH})$, which are widely used to obtain chain products of fine organic synthesis and petro chemistry, is very attractive ${ }^{1-6}$. Currently, the production of aromatic hydrocarbons based on the processing of petroleum in the process of catalytic reforming and pyrolysis. The most promising and effective for processing components of natural gas and methanol into aromatic hydrocarbons are catalysts based on high-silicon zeolites of the type ZSM-5 $5^{6-13}$. Typically, such catalysts are prepared by ion exchange or impregnation of a zeolitic carrier with solutions of compounds of the corresponding elements. However, the small ion exchange capacity of ZSM-5 zeolites limits the amount of input metals, and it is difficult to achieve uniform distribution of modifiers throughout the zeolite during impregnation. Meanwhile, the solid-phase modification (SPM) method, which was not based on the interaction of oxides, salts or carbonyls of transition elements with a zeolite matrix, turned out to be very promising ${ }^{15,16}$. By this method, it is possible to stabilize metals in the channels and cavities of zeolites and synthesize metal-containing zeolite systems in one stage without the use of solvents.

This article presents the results of studying the effect of additives of nanoscale powders (RUP) on the acid and catalytic properties of ZSM-5 zeolite in the process aromatization components of natural gas and methanol.

Experimental part: The catalysts are prepared by the method of mechanical mixing of zeolite HZSM-5 and nano-sized powders (RUP) of Mo and Cr in a vibratory mill for 4 hours, after which the prepared mixtures were calcined at a temperature of $550^{\circ} \mathrm{C}$ for 4 hours. The protonic parent H-ZSM-5 zeolite was obtained by ion-exchange of commercially available ZSM-5 (Nizhergorodskie sorbenty Ltd, Russia, $\mathrm{SiO}_{2} / \mathrm{Al}_{2} \mathrm{O}_{3}=33$ ) with $\mathrm{NH}_{4} \mathrm{Cl}$ and following calculations this, 10,0q ZSM-5 was refluxed twice in $200 \mathrm{ml}$ of $1.0 \mathrm{M} \mathrm{NH} \mathrm{NH}_{4} \mathrm{Cl}$ solution for $6 \mathrm{~h}$ and then calcined (in air) at $550^{\circ} \mathrm{C}$ for $4 \mathrm{~h} . \mathrm{Cr}, \mathrm{Mo}, \mathrm{Ni}, \mathrm{Zn}$ and V nanopowders were obtained by the method of electrically exploding conductors in $\operatorname{argon}^{14}$. The Mo content in the zeolite was 2, 0-6,0 wt. \% and the Cr concentration in the catalytic system 4,0\% Mo/HZSM5 varied from $4.0 \% \mathrm{Mo} / \mathrm{HZSM}-50.5$ to $1.5 \mathrm{wt} . \%$

As a source of raw materials used freshly distilled methanol (purity 99.0\%) and natural gas with composition (wt. \%): methane-84,1; ethane-4,5; propane-6,7; butanes-4,2; pentane-0,5.

The conversion of natural gas and methanol was carried out in a flow-type installation in a quartz solution with a loading of $5 \mathrm{~cm}^{3}$ of catalyst at atmospheric pressure. The conversion of natural gas was studied in the temperature range of $650-750^{\circ} \mathrm{C}$ and a space velocity of $1000 \mathrm{~h}^{-1}$, and methanol in the temperature range of $300-450^{\circ} \mathrm{C}$ and a space flow rate of methanol equal to $2 \mathrm{~h}^{-1}$, allowing to determine the distribution of acid sites by strength and their concentration. The formation of coke deposits and their nature was studied using the thermal analysis method on an MOM (Hungary) derivatograph in the temperature range $20-800^{\circ} \mathrm{C}$. The sample $(300-400 \mathrm{mg})$ in a platinum crucible was heated in air at a rate of $10 \mathrm{~K} / \mathrm{min}$. 


\section{RESULTS AND THEIR DISCUSSION.}

Unmodified zeolite HZSM-5 has a low activity in the conversion of natural gas. A noticeable yield of aromatic hydrocarbons (ArH) was observed at $750^{\circ} \mathrm{C}$ and was $6,2 \mathrm{wt} . \%$ (Table 1).

Table 1: Influence of the process temperature on composition of natural gas conversion products in the presence of modified HZSM-5.

\begin{tabular}{|c|c|c|c|c|c|c|c|c|c|c|}
\hline \multirow[b]{2}{*}{$\mathrm{T},{ }^{0} \mathrm{C}$} & \multirow[b]{2}{*}{$\begin{array}{c}\text { Conversion } \\
\text { of natural } \\
\text { gas } \%\end{array}$} & \multicolumn{7}{|c|}{ Reaction yields, $\%$} & \multirow[b]{2}{*}{$\begin{array}{c}\text { Yield } \\
\text { ArH, \% }\end{array}$} & \multirow[b]{2}{*}{$\begin{array}{c}\mathrm{S}_{\mathrm{ArH}} * *, \\
\%\end{array}$} \\
\hline & & $\mathrm{H}_{2}$ & $\begin{array}{c}\text { Alkanes } \\
\mathrm{C}_{1}-\mathrm{C}_{4}\end{array}$ & $\begin{array}{c}\text { Alkanes } \\
\mathrm{C}_{2}-\mathrm{C}_{4}\end{array}$ & $\mathrm{C}_{6} \mathrm{H}_{6}$ & $\mathrm{C}_{6} \mathrm{H}_{8}$ & $\mathrm{C}_{10}-\mathrm{C}_{8}$ & $\begin{array}{c}\mathrm{ArH}^{*} \\
\mathrm{C}_{11^{-}} \\
\mathrm{C}_{12}\end{array}$ & & \\
\hline \multicolumn{9}{|c|}{ 4,0\% Мо/НЦВМ-33 } & & \\
\hline 650 & 19,0 & 2,90 & 48,1 & 1,48 & 4,86 & 0,10 & 9,47 & 0,29 & 14,72 & 77,5 \\
\hline 700 & 25,2 & 4,4 & 74,84 & 1,23 & 6,62 & 0,12 & 12,53 & 0,26 & 19,53 & 77,6 \\
\hline 750 & 34,8 & 6,4 & 65,20 & 0,97 & 11,36 & 0,05 & 15,64 & 0,25 & 27,30 & 78,6 \\
\hline \multicolumn{11}{|c|}{$0.5 \% \mathrm{Cr}-4,0 \% \mathrm{Mo} / \mathrm{HZSM}-33$} \\
\hline 650 & 21,53 & 3,52 & 78,42 & 1,21 & 5,12 & 0,06 & 11,23 & 0,39 & 16,8 & 78,0 \\
\hline 700 & 27,0 & 4,62 & 73,01 & 0,96 & 7,12 & 0,10 & 13,95 & 0,41 & 21,58 & 19,9 \\
\hline 750 & 39,5 & 6,98 & 60,5 & 0,75 & 12,54 & 0,11 & 18,56 & 0,56 & 31,77 & 80,4 \\
\hline \multicolumn{11}{|c|}{$1.0 \% \mathrm{Cr}-4,0 \% \mathrm{Mo} / \mathrm{HZSM}-33$} \\
\hline 650 & 23,1 & 3,75 & 76,9 & 0,98 & 8,79 & 0,05 & 9,18 & 0,35 & 18,37 & 79,5 \\
\hline 700 & 28,4 & 4,69 & 71,6 & 0,82 & 10,8 & 0,08 & 11,74 & 0,27 & 22,89 & 80,5 \\
\hline 750 & 41,4 & 7,29 & 58,6 & 0,69 & 14,36 & 0,12 & 17,86 & 1,08 & 33,42 & 80,7 \\
\hline \multicolumn{11}{|c|}{$1.5 \% \mathrm{Cr}-4,0 \% \mathrm{Mo} / \mathrm{HZSM}-33$} \\
\hline 650 & 18,54 & 3,23 & 81,46 & 1,16 & 5,12 & 0,10 & 8,78 & 0,15 & 14,15 & 76,3 \\
\hline 700 & 25,6 & 4,52 & 74,4 & 0,97 & 9,64 & 0,12 & 10,22 & 0,13 & 20,11 & 78,5 \\
\hline 750 & 35,22 & 6,89 & 64,78 & 0,86 & 12,47 & 0,05 & 14,74 & 0,21 & 27,47 & 77,9 \\
\hline
\end{tabular}

Zeolite modified by molybdenum nanopowder shows noticeable catalytic activity in the conversion of natural gas components into aromatic hydrocarbons (Fig. 1). With increasing process temperature up to $750^{\circ} \mathrm{C}$ and the concentration of molybdenum in the zeolite to $4.0 \mathrm{wt} . \%$ an increase in the concentration of benzene is observed. At $750^{\circ} \mathrm{C}$, the benzene yield is $11.4 \%$ by weight. A further increase in the concentration of molybdenum nanopowder to $6,0 \mathrm{wt} \%$ practically does not lead to an increase in the yield of benzene. Unlike benzene, the maximum yield of naphthalene is observed when the concentration of nanopowder in the zeolite is $6,0 \mathrm{wt}$. \%. It should be noted that the addition of molybdenum nanopowder to zeolite HZSM-5 dramatically increases its selectivity for aromatic hydrocarbons. In the temperature range of $650-750^{\circ} \mathrm{C}$, the selectivity of ArH formation on HZSM-5 is $36,7-46,2 \%$, whereas on the $4,0 \%$ Mo/HZSM-5 catalyst, it reaches 77, 5-78,6\%.

The addition to the Mo-containing zeolite nanopowder of the second modifier element leads to a change in its activity in the process of converting natural gas. Table 1 presents the results of studies of the effect of chromium nanopowder content in 4,0\% Mo/HZSM-5 on the degree of conversion of natural gas, the composition of its conversion products and selectivity for $\mathrm{ArH}$ in the temperature range $650-750^{\circ} \mathrm{C}$.

It is seen that the addition of $0,5 \mathrm{wt} . \% \mathrm{Cr}$ does not lead to a significant increase in benzene and naphthalene. The increase in the content of nanopowder in the molybdenum-containing catalyst to $1.2 \mathrm{wt}$. $\%$ leads to a significant increase in the yield of benzene. At 700 and $750^{\circ} \mathrm{C}$, the yield of benzene increases 
from $6,7 \mathrm{wt} . \%$ to $10,8 \mathrm{wt} . \%$ and from $11,2 \mathrm{wt} . \%$ to $14,4 \mathrm{wt} . \%$. Increasing the content of $\mathrm{Cr}$ nanopowder in the catalyst to $1,5 \mathrm{wt}$. \% reduces the yield of benzene. It should be noted that the addition of $\mathrm{Cr}$ nanopowder to the Mo-containing in an amount of $0,5-1,0 \mathrm{wt}$. \% leads to a gradual decrease in the naphthalene yield.

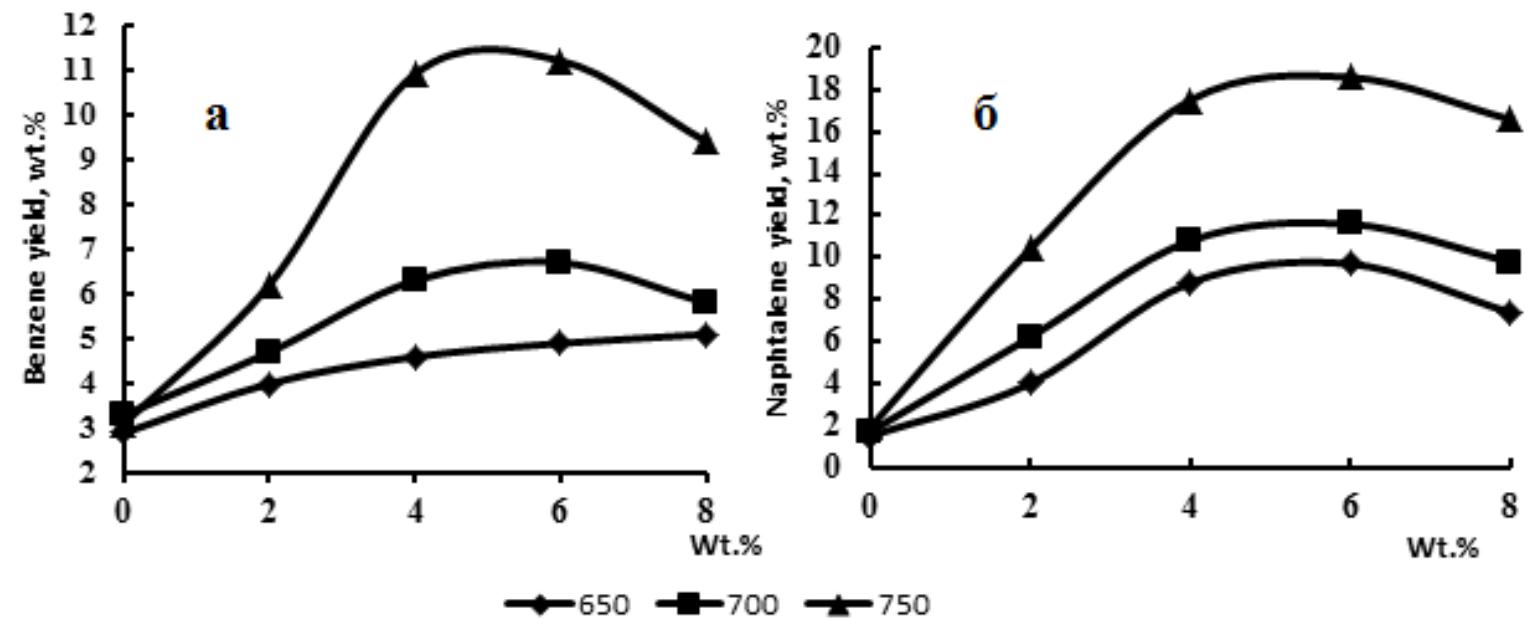

Fig. 1: Effect of molybdenum concentration on the yield of benzene (a) and naphthalene (b), wt.\%

Thus, the addition of $1,0 \mathrm{wt} . \% \mathrm{Cr}$ nanopowder to the Mo-containing catalyst leads to an increase in the conversion of natural gas and selectivity to ArH. The maximum output of the most valuable product of benzene is observed on a catalyst containing $1.0 \mathrm{wt} . \% \mathrm{Cr}$ nanopowder and at $750^{\circ} \mathrm{C}$ was $14,4 \mathrm{wt}$. \% with a selectivity of $80,7 \%$.

Figure 2 presents the results of studies of the influence of the nature of the second modifier element with their content of $1,0 \mathrm{wt} . \%$ in the catalyst composition of $4,0 \%$ Mo /HZSM-5 on the degree of conversion of natural gas and the yield of benzene at a temperature of $750^{\circ} \mathrm{C}$. It is seen that chromium has the highest promoting effect on the catalyst activity of $4,0 \% \mathrm{Mo} / \mathrm{HZSM}-5$ in the output of benzene. By increasing the degree of conversion and yield of benzene, bimetallic catalysts are placed in the next row;

\section{Cr-Mo/HZSM>Zn-Mo/HZSM-5>Ni-Mo/HZSM-5.}

Thus, studies have shown the possibility of direct chemical processing of natural gas components into liquid products using bimetallic zeolite systems.

Based on the composition of the products obtained on various catalytic systems, the dependence of their yield and selectivity of formation on the conditions of the process revealed the laws governing the transformation of the components of natural gas. It is established that the additional introduction of chromium nanopowder into HZSM-5, containing molybdenum nanoparticles, leads to an increase in the activity and selectivity of the catalyst in the formation of aromatic hydrocarbons from natural gas.

It was shown in $^{2,12,13}$ that when modifying HZSM-5 zeolite with solutions of ammonium hydrogen phosphate salts and rare-earth metal nitrates followed by calcination at $550^{\circ} \mathrm{C}$, it has a para-orienting effect on the distribution of xylene isomers during methanol conversion. Modification of HZSM-5 with $\mathrm{Zr}$ and $\mathrm{Mo}^{15}, \mathrm{Zr}$ and $\mathrm{W}^{16}$ nanopowders also has a para-orienting effect on its catalytic properties during the conversion of methanol. 


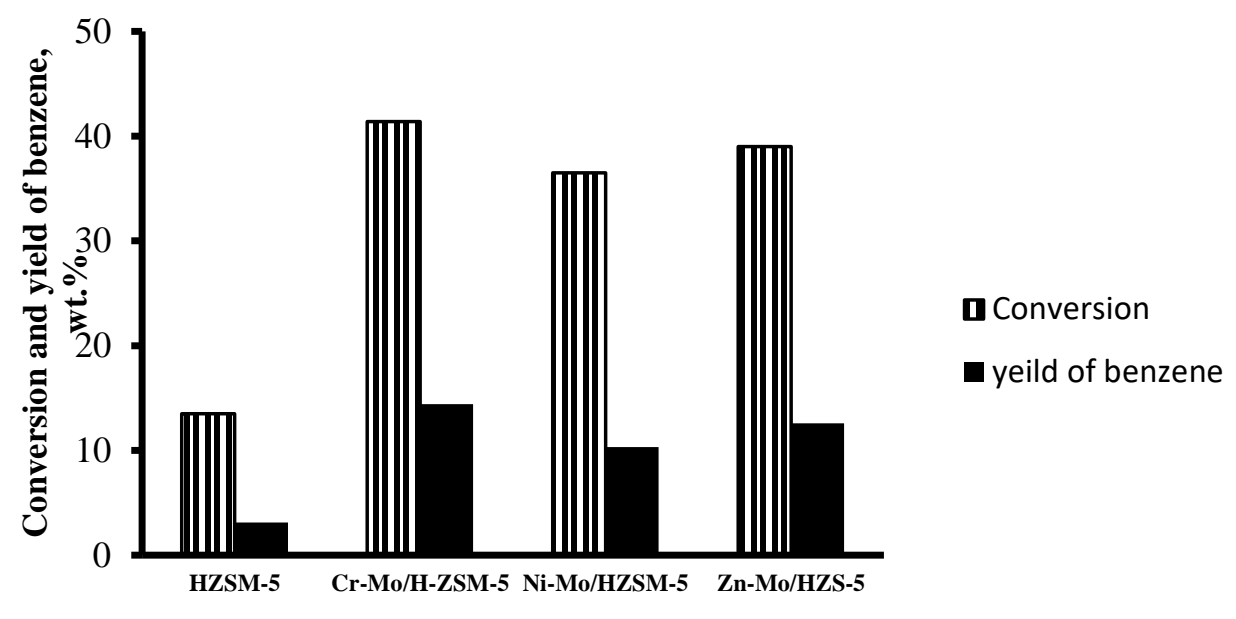

Fig. 2. The dependence of the conversion and yield of benzene on the nature of the second modifying metal (the content of the modifying metal is $1.0 \mathrm{wt} . \%$ )

Fig. 3 presents the results of studies of the influence of the concentration of $\mathrm{Cr}$ nanopowder in the composition of the $4,0 \% \mathrm{Mo} / \mathrm{HZSM}-5$ catalyst on the yield of aromatic hydrocarbons and selectivity for p-xylene during methanol conversion.

It is seen that the addition of $\mathrm{Cr}$ nanopowder in the amount of $0,5 \mathrm{wt} . \%$ to the composition of the Mocontaining catalyst has little effect on the yield of ArH and selectivity for p-xylene. The increase in the content of $\mathrm{Cr}$ nanopowder in the catalyst to $1,5 \mathrm{wt}$. \% slightly reduces the yield of $\mathrm{ArH}$ (from $24,5 \mathrm{wt}$. \% to $20,1 \mathrm{wt} . \%$ ), but significantly increases the selectivity for p-xylene (from $37,5 \%$ to $50 \%$ ). The increase in the content of nanopowder in the catalyst to 3,0wt. \% leads to a sharp increase in the selectivity for pxylene (to 68,0\%), but there is a noticeable decrease in the yield of ArH to 17, 8 wt. \%. The largest increase in $\mathrm{Cr}$ nanopowder in the catalyst dramatically reduces the yield of $\mathrm{ArH}$ (to 13,5wt. \%). Selectivity for p-xylene increases to $72,5 \%$.

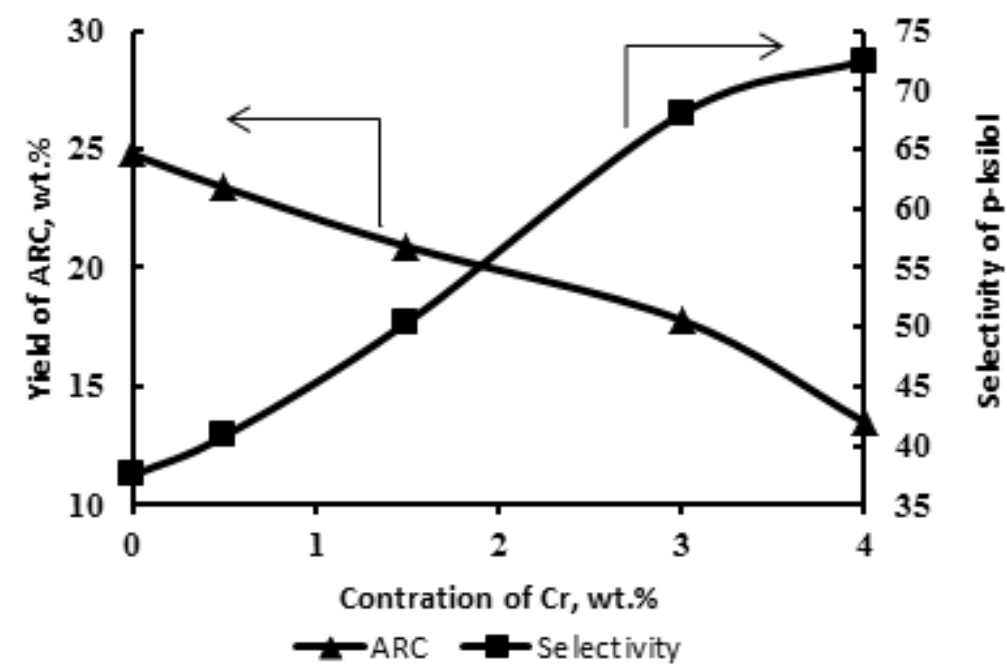

Fig. 3: The dependence of the yield of aromatic hydrocarbons and selectivity for $p$-xylene from the concentration of chromium in the composition of the catalyst $4 \% \mathrm{Mo} / \mathrm{HZSM}-5$ 
Fig .4 presents the results of studies of the influence of the nature of the modifiers in the composition of the $4,0 \% \mathrm{Mo} / \mathrm{HZSM}-5$ catalyst on the yield of ArH and the selectivity for p-xylene. It is seen that the smallest yield of $\mathrm{ArH}$ and selectivity for p-xylene is observed on the catalyst modified with nickel. The output of ArH catalysts modified by $\mathrm{Cr}, \mathrm{Zn}$ and $\mathrm{V}$ nanopowders differ little from each other. However, the selectivity of the formation of $p$-xylene, they differ significantly. The highest selectivity for $p$-xylene is shown by a modified vanadium nanopowder catalyst. The selectivity of the formation of $p$-xylene catalysts are located in a row

\section{V-Mo/HZSM-5>Zn-Mo/HZSM-5>Cr-Mo/HZSM-5>Ni-Mo/HSZM-5.}

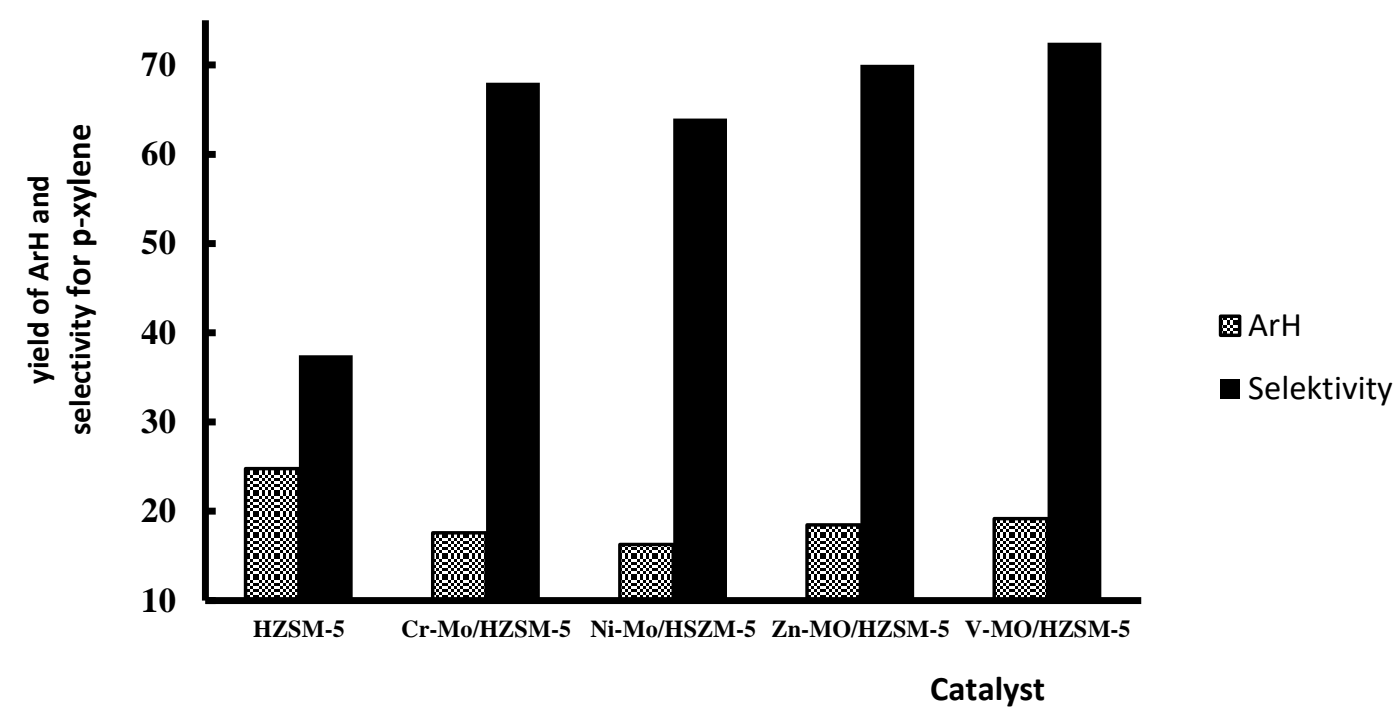

Fig .4: The dependence of the yield of aromatic hydrocarbons and selectivity for p-xylene on the nature of the modifying metal in the composition of the catalyst $4 \% \mathrm{Mo} / \mathrm{HZSM}-5$

\section{CONCLUSION}

Thus, the obtained results show the efficiency of using bimetallic Mo-containing catalysts of $\mathrm{Cr}$ and $\mathrm{V}$ modified with nanopowders to solve the problem of rational use of natural gas and methanol as a cheap and affordable raw material in order to produce aromatic hydrocarbons.

\section{REFERENCES}

1. S.N.Khadzhiev, N.V. Kolisnichenko,N.N. Ezhova ; Petroleum chemistry, 2008, 48(5), 323.

2. A.V. Vosmerikov, S.V. Kudryashov, Qazochimiya, 2010, 12, 62.

3. E.V.Matus, O.B. Sukhova, I.Z. Ismagilov, L.T. Tsikoza, Z.R. Ismagilov; Reaction Kinetics and Catalysis Letters. 2009, 98, 59.

4. H.A. Zaidi, K.K. Pant; Korean Journal of Chemical Engineering, 2005, 22, 353

5. S. Teketel, M.W. Erichsen, F.L. Bleken, S. Svelle, K.P. Lillerud, U. Olsbye; Catalysis, 2014, 2(24), 179.

6. J. Matthew, W.S. Teketel, B. Ipek, R.F. Lobo; Chemical Communications, 2015, 51(21), 4447. 
7. A.K. Aboul-Gheit, A.E. Awadallah, S.M. El-Kossy, A.-L.H. Mahmoud; Journal of Natural Gas Chemistry, 2008, 17(4), 337.

8. A.V. Vosmerikov, V.I. Zaykovskiy, L.L. Korobitsyna, E.G. Kodenev, V.V. Kozlov, G.V. Echevskii ; Studies in Surface Science and Catalysis, 2006, 162, 913.

9. S.S. Masiero, N.R. Marcilio, O.W. Perez-Lopez; Catalysis Letters, 2009, 131, 194.

10. L.N. Vosmerikova, E.I. Litvak, A.V. Vosmerikov, N.V. Usheva; Petroleum Chemistry, 2010, 50(3), 200.

11. L.L. Korobitsina, N.V. Arbuzova, A.V. Vosmerikov; Journal of Physical Chemistry, 2013, 87(6), 941.

12. L. N. Vosmerikova, A.V. Vosmerikov, Ya.E. Barbash, Zaykovskiy, V.V. Kozlov; Petroleum Chemistry, 2009, 49(1), 50.

13. T.A. Babayeva, E.A. Qanbarova, S.E. Mammadov, S.E. Mirzaliyeva, T.A. Aliyev, N.M. Allazov; Jecet Sec. C, 2017., 7(1). 01.

14. D. Ma, Y. Shu, X. Bao , Y. Xu, X. Han; Journal of Catalysis, 2000, 189(2), 314.

15. T.A. Babayeva, S.F. Mammadov, E.I. Ahmadov; Jecet Sec. A., 2016, 5(1), 89.

16. S.E. Mamedov, I.Sh. Gendjaliyeva, N.F. Akhmedova, Journal of Applied Chemistry, 2013, 86(1), 127.

* Corresponding Author: Nargiz Akhmedova;

Baku State Universitet, Azerbaijan, AZ1148, Baku. Z.Khalilov 23 